\title{
Centrosome amplification and multinuclear phenotypes are Induced by hydrogen peroxide
}

\author{
Sunyoung Chae', Chawon Yun ${ }^{2}$, \\ Haeryun Um ${ }^{1}$, Jae-Ho Lee ${ }^{1}$ \\ and Hyeseong $\mathrm{Cho}^{1,3}$ \\ 'Department of Biochemistry and Molecular Biology \\ Chronic Inflammatory Disease Research Center \\ Ajou University Schod of Medicine \\ Suwon 442-749, Korea \\ ${ }^{2}$ Laboratory of Gene Regulation and Development \\ NICHD, NIH, Bethesda, MD, USA \\ ${ }^{3}$ Corresponding author. Tel, 82-31-219-5052; \\ Fax, 82-31-219-5059, E-mail, hscho@ajou.ac.kr
}

Accepted 7 July 2005

Abbreviations: DAPI, 4, 6-diamidino-2-phenylindole; ERK, extracelIular signal-regulated kinase; MTOC, microtubule-organizing center, NAC, N-acetylcysteine; PDTC, pyrrolidinedithiocarbamate

\begin{abstract}
Multinucleated cells resulted from mitosis defect have been noted in pathophysiological states of the cells such as inflammation, senescence and cancer. Since oxidative stress has been known to correlate with these pathophysiological conditions, we tested the effect of $\mathrm{H}_{2} \mathrm{O}_{2}$ on the cell cycle progression and formation of multinucleated cells. $\mathrm{H}_{2} \mathrm{O}_{2}$ induced a significant delay in cell cycle progression in Chang Iiver cells. Interestingly, $\mathrm{H}_{2} \mathrm{O}_{2}$ actively induced hyperamplification of centrosomes ( $n \geq 3$ ) and multipolar spindle formationduring mitosis and subsequently increased the generation of multinucleated cells. A significant increase of the phospho-ERK level was observed upon $\mathrm{H}_{2} \mathrm{O}_{2}$ treatment but PD98059, an MEK1/2 inhibitor, didn't reduce the frequency of cells with hyperamplified centrosomes. On the other hand, treatment of either $\mathrm{H}_{2} \mathrm{O}_{2}$ or adriamycin increased intracellular ROS levels and multinucleated cells, which were significantly suppres sed by antioxidants, $\mathrm{N}$-acetylcysteine and PDTC. Thus, our results suggest that oxidative stress can trigger centrosome hyperamplification and multinucleated cell formation, which may promote pathophysiological progression.
\end{abstract}

Keywords: antioxidants; centrosome, giant cells, hydrogen peroxide, reactive oxygen species

\section{Introduction}

Centrosome is an important cellular organelle and plays a key role in cell division. The centrosome functions as a microtubule-organizing center (MTOC), which controls the polarity of microtubules in interphase and generates bipolar mitotic spindles during mitosis (Lange, 2002). Centrosome abnormalities with an excess number of centrosomes organize multipolar mitotic spindles, which pull the chromosomes in multiple directions, consequently increasing the chance of multinucleated cell formation and aneuploidy (D'Assoro et al., 2002). Aneuploidy is a characteristic feature of cancer and found in virtually every type of human cancer. Interestingly, mutations of p53, Brca1 and Brca2 tumor suppressor genes and amplification of cyclin $\mathrm{E}$ and aurora $\mathrm{A}$ genes found in multiple origins of cancer are also highly correlated with supernumerary centrosomes (Bertwistle and Ashworth, 1999; Jeng et al., 2004; Kawamura et al., 2004).

Centrosome abnormalities are also described in some aging cells. Centrosome and microtubule network during meiosis were significantly altered in aging oocytes of Drosophila, resulting in aneuploidy or trisomic zygotes (Shatten et al., 1999). Fibroblasts derived from Huntington's disease, a progressive neurodegenerative disorder, were found to have a high frequency of multiple centrosomes and aneuploidy (Sathasivam et al., 2001). However, unlike in cancer, molecular features involved in centrosome abnormalities in aging have never been proposed. In the present study, we demonstrated that oxidative stress can induce supernumerary centrosomes and multinucleated cell formation, which may promote pathophysiological progression during aging.

\section{Materials and Methods}

Cell cycle synchronization and cell cycle analysis Human Chang liver cells were originally purchased from ATCC and maintained in DMEM supplemented with $10 \%$ fetal bovine serum, $100 \mathrm{IU} / \mathrm{ml}$ penicillin, and $100 \mu \mathrm{g} / \mathrm{ml}$ streptomycin in a humidified $\mathrm{CO}_{2}$ incubator. Cells were synchronized by the double 
thymidine block (DTB) method at the G1/S boundary and released for cell cycle progression (Yun et al., 2004). Briefly, $2 \mathrm{mM}$ of thymidine was incubated for $18 \mathrm{~h}$ and followed by $6 \mathrm{~h}$ release. The $2^{\text {nd }}$ incubation of thymidine was carried out for 18 h. $\mathrm{H}_{2} \mathrm{O}_{2}(0.1-0.2$ $\mathrm{mM}$ ) was added right after removal of $2^{\text {nd }}$ thymidine. At each time point, cells were trypsinized, pelleted, and fixed with $70 \%$ cold ethanol for $30 \mathrm{~min}$ (Kim et al., 2005). Cells were then resuspended in a solution containing propidium iodide and subjected to FACScan analysis using a FACS Vantage flow cytometer (Becton Dickinson).

\section{Indirect immunofluorescence}

Cells were synchronized by the DTB method and $\mathrm{H}_{2} \mathrm{O}_{2}$ was added right after removal of $2^{\text {nd }}$ thymidine, followed by $12-24 \mathrm{~h}$ incubation. To obtain mitotic cells, $100 \mathrm{ng} / \mathrm{ml}$ of nocodazole was co-incubated with $\mathrm{H}_{2} \mathrm{O}_{2}$ for 8-12 h. The cells released from nocodazole arrest were grown on poly-L-lysine-coated cover glasses and allowed to further progress into mitosis. Cells were fixed with the mixture of methanol/acetone (1:1) solution and permeabilized with $0.5 \%$ Triton $X-100$. Fixed cells were preincubated in blocking solution ( $5 \%$ BSA in PBS), followed by incubation with primary antibodies for pericentrin, $\gamma$ -tubulin or $\alpha$-tubulin overnight at $4{ }^{\circ} \mathrm{C}$. Cells were then washed three times with shaking and probed with fluorescence-conjugated secondary antibody for $1 \mathrm{~h}$ at room temperature. After washing, cells were mounted in the mounting solution containing 4', 6-diamidino-2-phenylindole (DAPI) and examined by fluorescence microscope (Zeiss) and analyzed with Aims software. For the accurate centrosome counting, antibodies against pericentrin were used and the number of centrosome was counted from 300-600 cells each time.

\section{Western blotting}

Western blotting was performed as described previously (Yun et al., 2004). Briefly, harvested cell pellets were extracted with RIPA buffer, and the resultant extracts were subjected to a SDS-PAGE and probed with anti-cyclin A antibody (Santa Cruz Laboratory). The enhanced chemiluminescence (ECL) non-radioactive detection system was used to detect the antibody-protein complexes.

\section{Measurement of intracellular ROS level}

Intracellular ROS levels were determined by using an oxidative-sensitive fluorescence dye, dichlorodihydrofluorescein diacetate (DCF-DA, Molecular Probes) as we previously described (Wang et al., 2003). Cells were treated with $0.2 \mathrm{mM}$ of $\mathrm{H}_{2} \mathrm{O}_{2}$ or $0.1 \mu \mathrm{g} / \mathrm{ml}$ of adriamycin for $24 \mathrm{~h}$ and further incubated with 10 $\mu \mathrm{M}$ of DCF-DA for $15 \mathrm{~min}$. Unincorporated fluorescent dye was washed out with PBS and the intensities of fluorescence in cells were analyzed using FACS Vantage at the wavelength of $526 \mathrm{~nm}$.

\section{Results and Discussion}

\section{$\mathrm{H}_{2} \mathrm{O}_{2}$ Induces hyperamplification of centrosome and multipolar mitotic spindle formation}

Multinucleated cells were often described in cells under pathophysiological conditions such as inflammation, senescence and cancer (Devaney et al., 1992, Protzer et al., 1996; Evans 2002; Ren et al., 2005). Prolonged oxidative stress has been described as a common causative factor for these diseases. Since $\mathrm{H}_{2} \mathrm{O}_{2}$ has been most commonly used inducer for imposing oxidative stress or stressinduced premature senescence, we attempted to investigate whether centrosome abnormalities were involved in increasing genomic instability in cells under oxidative stress. Chang liver cells treated with $0.1 \mathrm{mM}$ of $\mathrm{H}_{2} \mathrm{O}_{2}$, a subcytotoxic concentration, showed a significant delay in cell cycle progression (Figure 1A). In control Chang cells, cells G1 entered $\mathrm{G} 2 / \mathrm{M}$ phase in $9 \mathrm{~h}$ after release and returned back to $\mathrm{G} 1$ phase in $12 \mathrm{~h}$, completing another cell division in $18 \mathrm{~h}$. On the other hand, Chang cells exposed to $\mathrm{H}_{2} \mathrm{O}_{2}$ entered $\mathrm{G} 2 / \mathrm{M}$ phase in $12 \mathrm{~h}$ and slowly progressed to $\mathrm{G} 1$ phase in $30 \mathrm{~h}$. These cells accumulated at $\mathrm{G} 1$ phase by $48 \mathrm{~h}$ and underwent senescence-like morphology such as enlarged and flattened cell shape (data not shown). A significant degradation of cyclin A level was accmpanied at 12 $\mathrm{h}-15 \mathrm{~h}$ where cells were staggered at $\mathrm{G} 2 / \mathrm{M}$ phase in the presence of $\mathrm{H}_{2} \mathrm{O}_{2}$ (Figure $1 \mathrm{~B}$ ). When these flattened cells were stained with antibody for centrosome-specific pericentrin, some of them contained more than three centrosomes with tripolar directional chromosomal staining (Figure $1 \mathrm{C}, \mathrm{b}$ ). When the patterns of chromosome segregation with $\alpha$-tubulin were overlaid, multipolar spindles radiating from the spindle poles as well as multidirectional segregation of chromosomes were increased in Chang cells exposed to $\mathrm{H}_{2} \mathrm{O}_{2}$ (Figure $1 \mathrm{C}, \mathrm{c}$ ). When these cells were further progressed into $\mathrm{G} 1$ phase, multinucleated cells with supernumerary centrosomes (Figure $1 \mathrm{C}$, d) were found after staining cells with anti- $\gamma$-tubulin antibody. At least, $20 \%$ of Chang cells exposed to $\mathrm{H}_{2} \mathrm{O}_{2}$ were identified to contain supernumerary centrosomes whereas $5-7 \%$ of control Chang cells showed abnormal centrosome numbers. Similarly, the number of cells containing multiple nuclei was increased twice upon $\mathrm{H}_{2} \mathrm{O}_{2}$ treatment. The data here show that $\mathrm{H}_{2} \mathrm{O}_{2}$ actively induced 
A

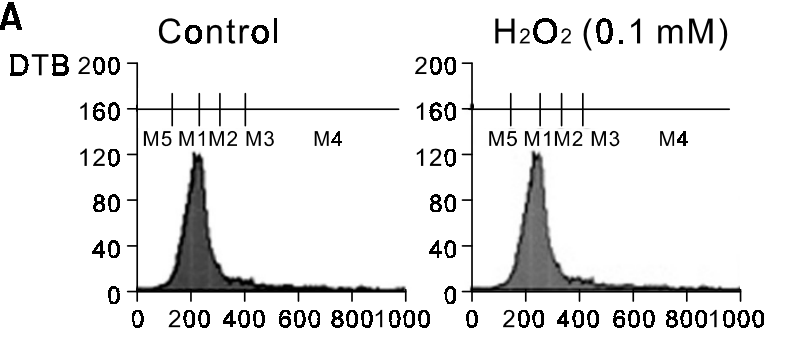

$6 \mathrm{~h} 120$

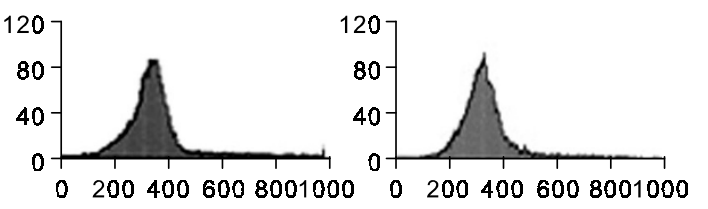

9 h 120
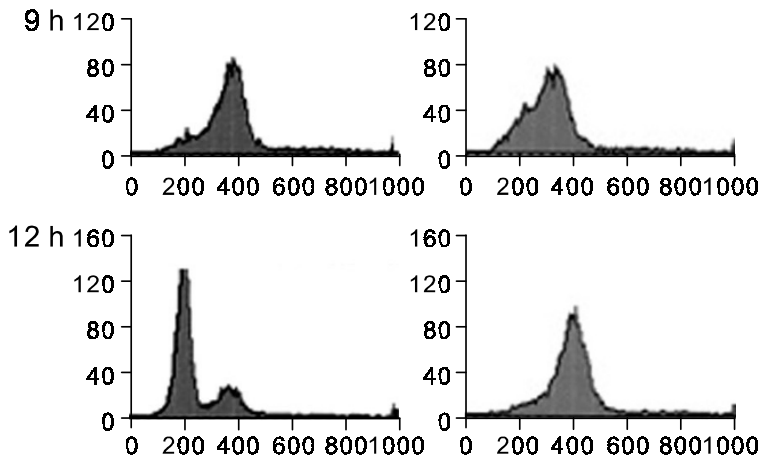

$18 \mathrm{~h} 120$
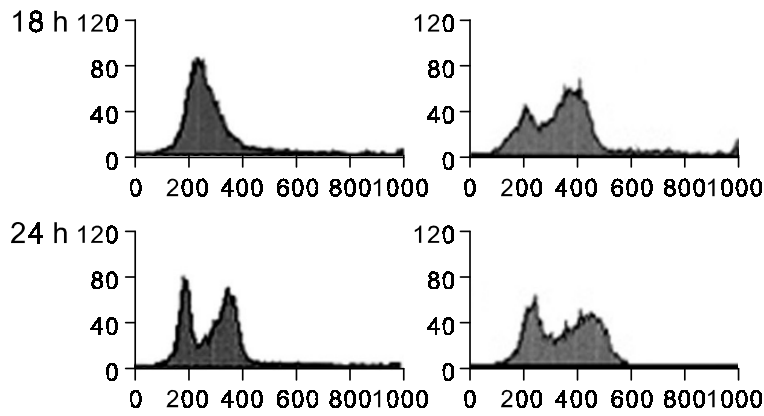

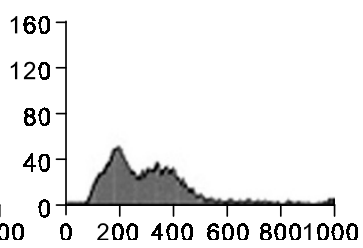

B

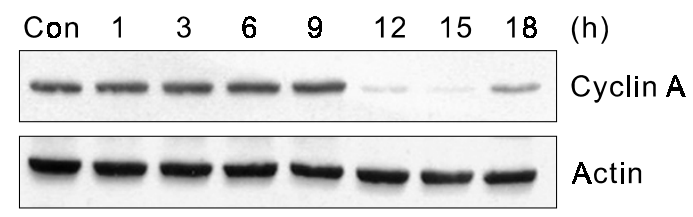

C

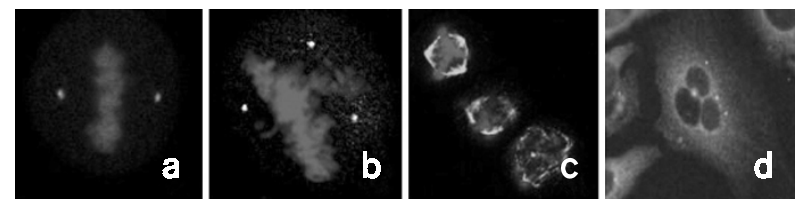

d

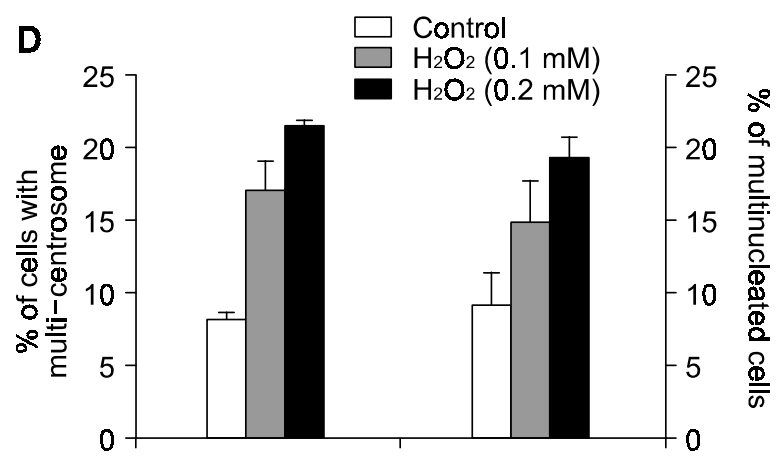

Figure 1. $\mathrm{H}_{2} \mathrm{O}_{2}$ induces hyperamplification of centrosome and multipolar mitotic spindle formation. (A) FACS analysis of cell cycle progression after $\mathrm{H}_{2} \mathrm{O}_{2}$ treatment. (B) Determination of cyclin A level upon $\mathrm{H}_{2} \mathrm{O}_{2}$ treatment. (C) Immunofluorescence staining of centrosome-specific pericentrin staining. The Chang cells released from the DTB were treated with $0.1 \mathrm{mM}$ of $\mathrm{H}_{2} \mathrm{O}_{2}$ and subsequently with $100 \mathrm{ng} / \mathrm{ml}$ of nocodazole. Centrosomes were visualized by staining cells with anti-pericentrin antibody and DAPI $(a, b)$. The overlaid image of mitotic spindles and chromosomal staining (c) and multinucleated cells visualized by anti- $\gamma$-tubulin staining (d). (D) Quantification of supernumerary centrosomes and multinucleated cells after $\mathrm{H}_{2} \mathrm{O}_{2}$ treatment. Bar represents mean \pm standard deviation.

amplification of centrosomes $(n \geq 3)$ and multipolar spindle formation during mitosis and subsequently increased the generation of multinucleated cells.
The ERK pathway does not mediate the formation of supernumerary centrosomes

Increase of intracellular reactive oxygen species (ROS) level can activate several stress signaling pathways, which may partly trigger senescence 
A

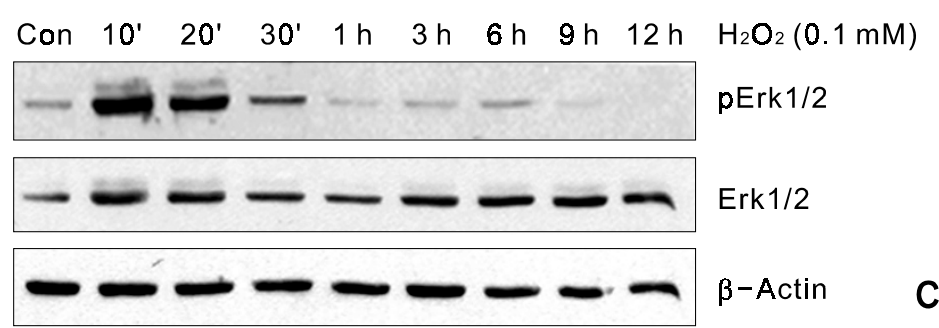

B
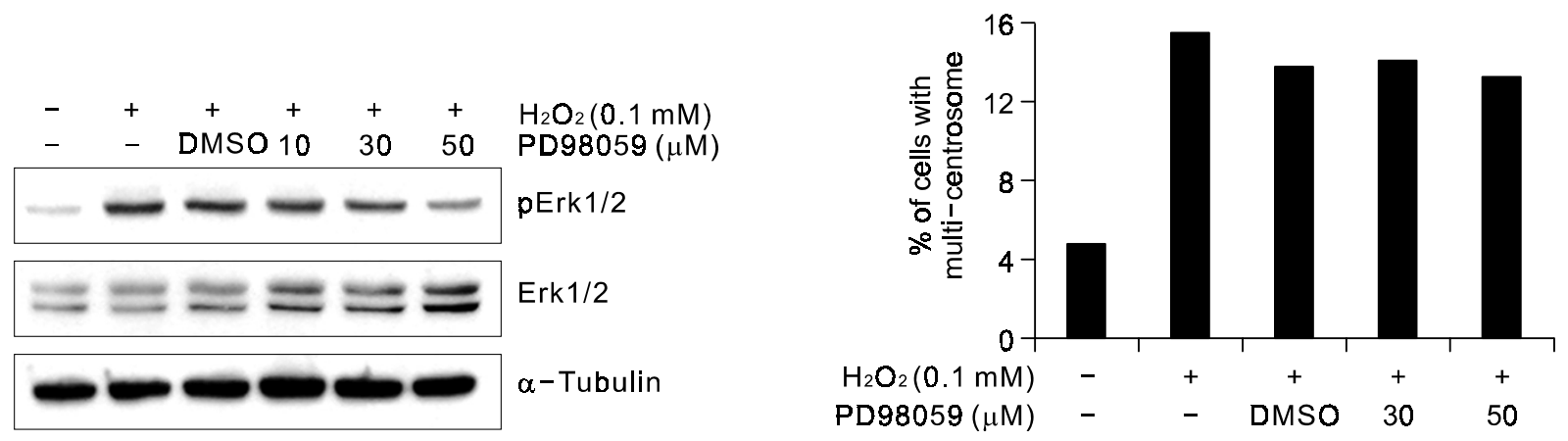

Figure 2. The ERK pathway does not mediate the formation of supernumerary centrosomes. (A) Immunoblotting of the phospho-ERK levels after $\mathrm{H}_{2} \mathrm{O}_{2}$ treatment. (B) Suppression of the phosphor-ERK by PD98059. (C) Suppression of the ERK pathway did not affect supernumerary centrosomes.

program (Leonard et al., 2004). Ras/MAPK pathway is one of the most widely described signaling pathways, which were activated under oxidative stress (Hutter et al., 2002). We and other group reported that the activation of Ras/ERK mediated hyperamplification of centrosomes in cells exposed to $\gamma$-radiation or overexpressing HBx viral oncoprotein (Saavedra et al., 1999; Yun et al., 2004). Therefore, the effect of ERK inhibitor on the centrosome amplification was examined using different concentrations of PD98059, an MEK1/2 inhibitor. When cells were exposed to $0.1 \mathrm{mM}$ of $\mathrm{H}_{2} \mathrm{O}_{2}$, a significant induction of phopho-ERK level was observed in 10-20 min (Figure 2A). Preincubation of cells with 50 $\mu \mathrm{M}$ of PD98059 $1 \mathrm{~h}$ before addition of $\mathrm{H}_{2} \mathrm{O}_{2}$ almost completely suppressed the increase of phosphoERK level (Figure 2B). However, these concentrations of PD98059 did not reduce the frequency of supernumerary centrosomes in cells exposed to $\mathrm{H}_{2} \mathrm{O}_{2}$ (Figure $2 \mathrm{C}$ ). Thus, the ERK pathway does not mediate supernumerary centrosomes in cells under oxidative stress.

\section{Inhibition of intracellular ROS levels reduced the occurrence of multinucleated cells}

In order to further delineate a correlation between oxidative stress and aberrant chromosome segregation and multinucleated cell formation, we employed adriamycin, a chemotherapeutic agent. It has been reported that adriamycin imposed a severe oxidative stress in cells (Childs et al., 2002; Deepa and Varalakshmi, 2003). When we determined the intracellular ROS levels after treatment of $0.2 \mathrm{mM}$ of $\mathrm{H}_{2} \mathrm{O}_{2}$ or $0.1 \mu \mathrm{g} / \mathrm{m}$ of adriamycin, a subcytotoxic concentration, evident increase of ROS levels was observed (Figure 3A). The median value of fluorescence intensities in control Chang was increased by $\sim$ twice upon $\mathrm{H}_{2} \mathrm{O}_{2}$ treatment. Similarly, the median value of fluorescence intensities was also shifted to the right, showing $\sim$ three times increase in ROS generation by adriamycin treatment. We found that adriamycin also significantly increased the generation of multinucleated cells in Chang cells (Figure 3B). We also found that pretreatment of antioxidants such as $20 \mathrm{mM}$ of NAC or $50 \mu \mathrm{g} / \mathrm{ml}$ of PDTC significantly reduced the frequency of multinucleated cell generation. These results demonstrated oxidative stress increased generation of multinucleated cells, at least mediated through centrosome hyperamplification.

In the present study, we have demonstrated that $\mathrm{H}_{2} \mathrm{O}_{2}$ actively induced hyperamplification of centrosomes $(n \geq 3)$ and multipolar spindle formation during mitosis and subsequently increased the generation of multinucleated cells. Multinucleated cells can be found in normal muscle cells and in pathophysiological states of cells such as cancer, aging and inflammation (Devaney et al., 1992, Protzer et al., 1996; Evans 2002; Ren et al., 2005). Although, the exact role of multinucleated cells in these pathophysiological conditions is not clear, it certainly 
A
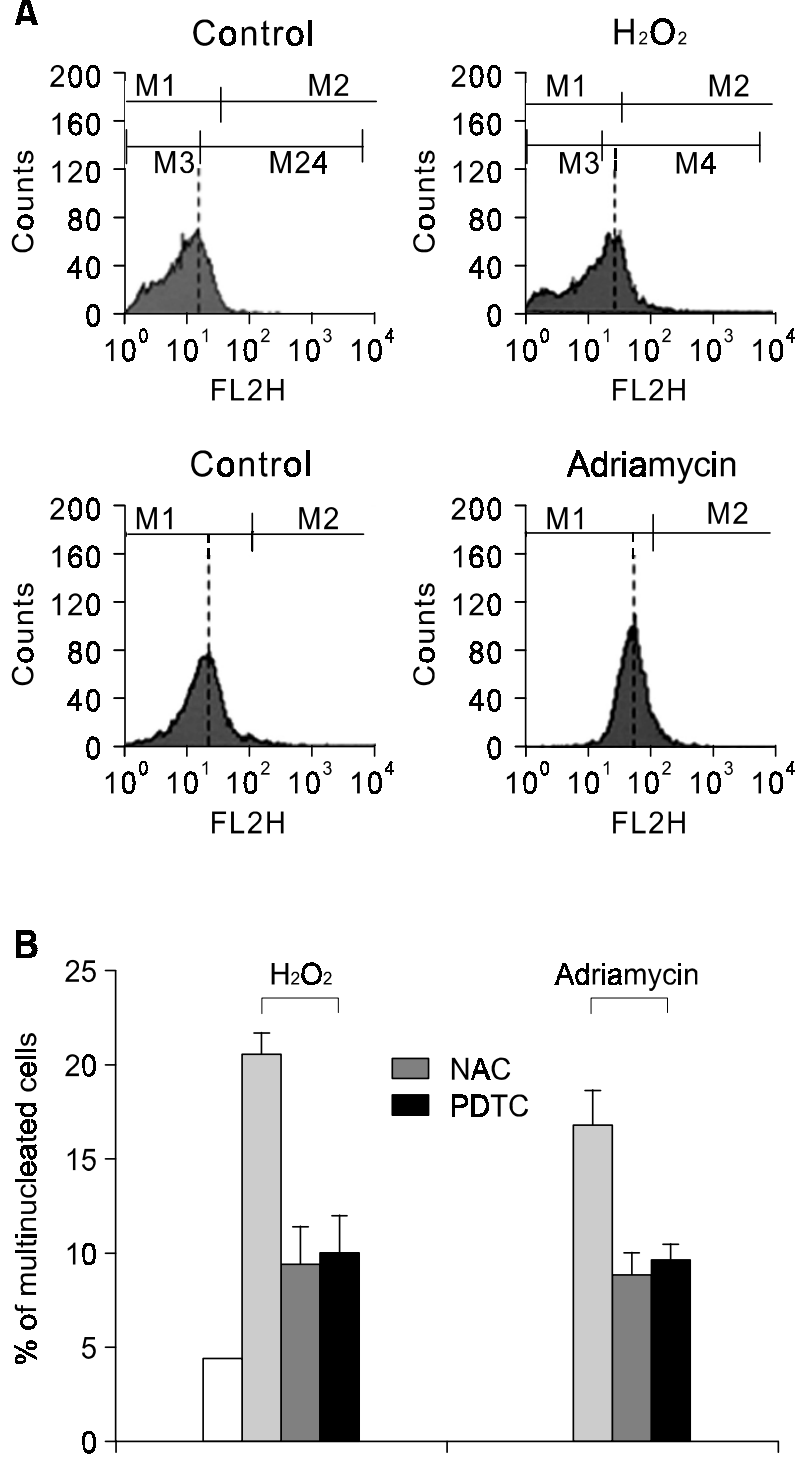

Figure 3. Inhibition of intracellular ROS levels reduced the occurrence of multinucleated cells. (A) Increase of intracellular ROS levels were determined by DCF-DA fluorescent dye and FACS Vantage. (B) Antioxidants, $20 \mathrm{mM}$ of NAC or $50 \mu \mathrm{g} / \mathrm{ml}$ of PDTC, significantly suppressed the generation of multinucleated cells induced by $0.2 \mathrm{mM}$ of $\mathrm{H}_{2} \mathrm{O}_{2}$ and 0.1 $\mu \mathrm{g} / \mathrm{ml}$ of adriamycin. Bar represents mean \pm standard deviation.

contributes to increase the genomic and morphological alterations during cell division. Importance of genomic instability in carcinogenesis can not be further emphasized (Park et al., 2005). Interestingly, genomic instability is also considered as one of the major causative factors in aging. It has shown that genomic instability accumulated through DNA damage and DNA repair defect triggers aging (Beckman and Ames, 1998; Mattson 2003). Our findings here propose that oxidative stress, which is highly correlated with both cancer and aging, can trigger cen- trosome hyperamplification, which contributes to increase genomic instability. Interestingly, recent studies on telomere shortening and maintenance provided an insight in understanding a possible link between cancer and aging (Blasco 2005; Rodier et al., 2005). Cells with telomere dysfunction do not divide and undergo senescence, accumulating genomic damage. However, those cells also encounter great risks of neoplastic transformation when cells acquired additional mutations in the p53 pathway or checkpoint function (Satyanarayana et al., 2004). We propose that centrosome hyperamplification induced by hydrogen peroxide is another way to increase the genomic instability in aging and cancer.

\section{Acknowledgement}

This study was supported by grant of Korea Science and Engineering Foundation through Chronic Inflammatory Disease Research Center (R13-2003-019).

\section{References}

Beckman KB, Ames BN. The free radical theory of aging matures. Physiol Rev 1998;78:547-81

Bertwistle D, Ashworth A. The pathology of familial breast cancer: how do the functions of BRCA1 and BRCA2 relate to breast tumour pathology? Breast Cancer Res 1999;1:41-7

Blasco MA. Mice with bad ends: mouse models for the study of telomeres and telomerase in cancer and aging. EMBO J 2005;24:1095-103

Childs AC, Phaneuf SL, Dirks AJ, Phillips T, Leeuwenburgh C. Doxorubicin treatment in vivo causes cytochrome $\mathrm{C}$ release and cardiomyocyte apoptosis, as well as increased mitochondrial efficiency, superoxide dismutase activity, and Bcl-2:Bax ratio. Cancer Res 2002;62:4592-8

D'Assoro AB, Lingle WL, Salisbury JL. Centrosome amplification and the development of cancer. Oncogene 2002;21: 6146-53

Deepa PR, Varalakshmi P. Protective effect of low molecular weight heparin on oxidative injury and cellular abnormalities in adriamycin-induced cardiac and hepatic toxicity. Chem Biol Interact 2003;146:201-10

Devaney K, Goodman ZD, Ishak KG. Postinfantile giant-cell transformation in hepatitis. Hepatology 1992;24:737-45

Evans HL. Multinucleated giant cells in plantar fibromatosis. Am J Surg Pathol 2002;26:244-8

Hutter E, Unterluggauer H, Uberall F, Schramek H, JansenDurr P. Replicative senescence of human fibroblasts: the role of Ras-dependent signaling and oxidative stress. Exp Gerontol 2002;37:1165-74

Jeng YM, Peng SY, Lin CY, Hsu HC. Overexpression and amplification of Aurora-A in hepatocellular carcinoma. Clin Cancer Res 2004;10:2065-71 
Kawamura K, Izumi H, Ma Z, Ikeda R, Moriyama M, Tanaka T, Nojima T, Levin LS, Fujikawa-Yamamoto K, Suzuki K, Fukasawa $\mathrm{K}$. Induction of centrosome amplification and chromosome instability in human bladder cancer cells by p53 mutation and cyclin E overexpression. Cancer Res 2004;64:4800-9

Kim MR, Kim HS, Lee MS, Lee MJ, Jang JJ. Cell cycle protein profile of the hepatic stellate cells (HSCs) in dimethylnitrosamine-induced rat hepatic fibrosis. Exp Mol Med 2005;37:335-42

Lange BM. Integration of the centrosome in cell cycle control, stress response and signal transduction pathways. Curr Opin Cell Biol 2002;14:35-43

Leonard SS, Harris GK, Shi X. Metal-induced oxidative stress and signal transduction. Free Radic Bio Med 2004; 37:1921-42

Mattson MP. Gene-diet interactions in brain aging and neurodegenerative disorders. Ann Intern Med 2003;139: 441-4

Park M, Park H, Kim WH, Cho J, Lee JH. Presence of autocrine hepatocyte growth facotr-Met signaling and its role in proliferation and migration of SNU-484 gastric cancer cell line. Exp Mol Med 2005;37:213-9

Protzer U, Dienes HP, Bianchi L, Lohse AW, HelmreichBecker I, Gerken G, Meyer zum Buschenfelde KH. Postinfantile giant cell hepatitis in patients with primary sclerosing cholangitis and autoimmune hepatitis. Liver 1996;16:274-82

Ren R, Sun X, Staerkel G, Sneige N, Gong Y. Fine-needle aspiration cytology of a liver metastasis of follicular dendritic cell sarcoma. Diagn Cytopathol. 2005;32:38-43
Rodier F, Kim SH, Nijjar T, Yaswen P, Campisi J. Cancer and aging: the importance of telomeres in genome maintenance. Int J Biochem Cell Biol 2005;37:977-90

Saavedra HI, Fukasawa K, Conn CW, Stambrook PJ. MAPK mediates RAS-induced chromosome instability. J Biol Chem 1999;274:38083-90

Sathasivam K, Woodman B, Mahal A, Bertaux F, Wanker EE, Shima DT, Bates GP. Centrosome disorganization in fibroblast cultures derived from R6/2 Huntington's disease (HD) transgenic mice and HD patients. Hum Mol Genet 2001;10:2425-35

Satyanarayana A, Manns MP, Rudolph KL. Telomeres and telomerase: a dual role in hepatocarcinogenesis. Hepatology 2004;40:276-83

Schatten $\mathrm{H}$, Chakrabarti A, Hedrick J. Centrosome and microtubule instability in aging Drosophila cells. J Cell Biochem 1999;74:229-41

Wang JH, Yun C, Kim S, Lee JH, Yoon G, Lee MO, Cho H. Reactive oxygen species modulates the intracellular level of HBx viral oncoprotein. Biochem Biophys Res Commun 2003;310:32-9

Yun C, Cho H, Kim SJ, Lee JH, Park SY, Chan GK, Cho H. Mitotic aberration coupled with centrosome amplification is induced by hepatitis $B$ virus $X$ oncoprotein via the Rasmitogen-activated protein/extracellular signal-regulated kinase-mitogen-activated protein pathway. Mol Cancer Res 2004;2:159-69 